\title{
Mask humidity during CPAP: influence of ambient temperature, heated humidification and heated tubing
}

This article was published in the following Dove Press journal:

Nature and Science of Sleep

\author{
Georg Nilius ${ }^{1,2}$ \\ Ulrike Domanski' \\ Maik Schroeder' \\ Holger Woehrle ${ }^{3,4}$ \\ Andrea Graml ${ }^{4}$ \\ Karl-Josef Franke ${ }^{1,2}$ \\ 'Helios Klinik Hagen-Ambrock, \\ Department of Pneumology, \\ Hagen, Germany; ${ }^{2}$ Department of \\ Internal Medicine, Witten-Herdecke \\ University, Witten, Germany; ${ }^{3}$ Sleep \\ and Ventilation Center Blaubeuren, \\ Respiratory Center Ulm, Ulm, \\ Germany; ${ }^{4}$ ResMed Science Center, \\ ResMed Germany, Martinsried, \\ Germany
}

Correspondence: Maik Schroeder Helios Klinik Hagen-Ambrock, Department of Pneumology, Ambrocker Weg 60, 5809I Hagen, Germany

Tel +49233I 9742083

Fax +49 233I 97452080

Email maik.schroeder@helios-kliniken.de
Purpose: Mucosal drying during continuous positive airway pressure (CPAP) therapy is problematic for many patients. This study assessed the influence of ambient relative humidity $(\mathrm{rH})$ and air temperature $(\mathrm{T})$ in winter and summer on mask humidity during CPAP, with and without mask leak, and with or without heated humidification \pm heated tubing.

Methods: CPAP ( 8 and $12 \mathrm{cmH}_{2} \mathrm{O}$ ) without humidification (no humidity [nH]), with heated humidification controlled by ambient temperature and humidity (heated humidity $[\mathrm{HH}]$ ) and $\mathrm{HH}$ plus heated tubing climate line (CL), with and without leakage, were compared in 18 subjects with OSA during summer and winter.

Results: The absolute humidity $(\mathrm{aH})$ and the T inside the mask during CPAP were significantly lower in winter versus summer under all applied conditions. Overall, absolute humidity differences between summer and winter were statistically significant in both $\mathrm{HH}$ and CL vs. nH $(p<0.05)$ in the presence and absence of mouth leak. There were no significant differences in $\mathrm{aH}$ between $\mathrm{HH}$ and CL. However, in-mask temperature during CL was higher $(p<0.05)$ and $\mathrm{rH}$ lower than during HH. In winter, CPAP with CL was more likely to keep rH constant at $80 \%$ than CPAP without humidification or with standard $\mathrm{HH}$.

Conclusion: Clinically-relevant reductions in aH were documented during CPAP given under winter conditions. The addition of heated humidification, using a heated tube to avoid condensation is recommended to increase $\mathrm{aH}$, which could be useful in CPAP users complaining of nose and throat symptoms.

Keywords: continuous positive airway pressure, humidification, temperature, leakage

\section{Introduction}

Acceptance of continuous positive airway pressure (CPAP) therapy may be compromised by side effects. Up to $70 \%$ of subjects using nasal CPAP report symptoms such as nasal congestion, dry nose and throat, sneezing, sore throat, epistaxis and discomfort associated with dry cold air. ${ }^{1-3}$ These may reduce the acceptance of therapy and CPAP efficacy. ${ }^{3,4}$ It has been shown that subjects on CPAP with mouth leakage for $>70 \%$ of their total sleep time (TST) had significantly lower compliance. ${ }^{5}$

Heated humidification (heated humidity $[\mathrm{HH}]$ ) prevents upper airway dryness and has been shown to significantly improve CPAP-related side effects. ${ }^{6-8}$ A number of studies have attempted to determine the relationship between HH use and CPAP compliance. While one showed a significant increase in compliance within $35 \mathrm{~min}$ of the addition of $\mathrm{HH},{ }^{9}$ two of three trials included in a meta-analysis found the addition of $\mathrm{HH}$ had no effect and the other reported a small but significant compliance 
improvement in the $\mathrm{HH}$ group. ${ }^{10}$ However, even with the addition of $\mathrm{HH}$, a decrease in relative humidity $(\mathrm{rH})$ during CPAP with mouth breathing cannot be fully prevented, and subjects may still experience nasal irritation and dryness. ${ }^{11}$ It is difficult to achieve optimal humidification because inspired air temperatures of $>30^{\circ} \mathrm{C}$ are not well tolerated. However, to minimize dehydration of the mucous membranes humidification is a useful addition to CPAP therapy. Buildup of condensation in the tube and mask is another potential issue during use of CPAP with HH. If saturation in the tube exceeds the dew point (100\% saturation), water vapor condenses and forms droplets, causing sleep disruption. ${ }^{12}$ Heated tubing has been developed which increases air temperature, improves the ability of inhaled gases to transport water, and prevents condensation. However, use of heated tubing has not yet been shown to improve compliance with CPAP. ${ }^{6}$

The ideal level of humidification during CPAP has not yet been clearly defined. Martins et $\mathrm{al}^{11}$ found that mouth leakage under CPAP during sleep reduced the $\mathrm{rH}$ from $60 \pm 14 \%$ to 43 $\pm 12 \%$. During periods of CPAP with mouth breathing, $\mathrm{HH}$ was able to increase the $\mathrm{rH}$ by up to $60 \pm 14 \%$, but this was still 20\% below rH achieved during $\mathrm{HH}$ without mouth leaks $(81 \pm 14 \%)$. $\mathrm{HH}$ values of $>80 \%$ during CPAP with mouth leakage can also be attained by using a face mask. ${ }^{11}$ However, many subjects find a nasal mask more comfortable than a face mask, ${ }^{13}$ but an $\mathrm{rH}$ value of $\geq 80 \%$ should be the target during CPAP using a nasal mask and with mouth leakage to ensure adequate hydration of the nasal and pharyngeal mucosa. Traditionally, CPAP HH devices had a single adjustable subject control which set the temperature of the water heater to a constant level throughout the night. This does not respond to changes in ambient temperature and humidity, potentially contributing to ineffective humidification. In contrast, new generation CPAP devices monitor set pressure, airflow, and ambient temperature and humidity, and can optimize $\mathrm{rH}$.

The influence of ambient conditions on humidity delivery of new CPAP humidification systems, and the impact of mask and mouth leak on humidity reaching the upper airway are not well understood. Therefore, this study assessed the extent to which humidity in the mask is influenced by $\mathrm{rH}$ and ambient air temperature ( $\mathrm{T}$ ) in two different seasons (winter and summer) and by mask leaks during CPAP, with and without heated humidification and with heated humidification using a heated tube.

\section{Methods}

Patients with obstructive sleep apnea (OSA) were eligible for this open-label observational study (NCT01462409).
The study protocol was approved by the ethics committee of the University of Witten-Herdecke. All patients gave written informed consent to participate in the trial, which was conducted in accordance with Good Clinical Practice and the Declaration of Helsinki.

\section{Study design}

Investigations were performed in the morning (09:45 to 11:45 h), in awake, supine subjects. The three different CPAP conditions were applied in a random order: CPAP with no humidification (no humidity $[\mathrm{nH}]$ ); CPAP with standard heated humidification $(\mathrm{HH})$; CPAP with heated humidification using a heated tube climate line (CL).

\section{Equipment}

The same CPAP device (S9; ResMed Germany, Martinsried, Germany) was used for all experiments. This device automatically regulates the temperature and $\mathrm{RH}$ of inhaled air using various sensors, including a temperature sensor in the tube near the mask. For HH experiments, the humidifier was set to the recommended level of 3 out of 6 , resulting in delivery of $80 \% \mathrm{rH}$ and a temperature of $27^{\circ} \mathrm{C}$. When using the heated tube, the system was set to a temperature of $27^{\circ} \mathrm{C}$ which provides approximately $80 \%$ relative humidity ( 21 $\mathrm{mg} / \mathrm{L}$ ambient humidity).

The temperature and humidity sensor was the Minihumidity/-temperature-Module 0628 0008, probe tip $49 \times$ $18 \times 7 \mathrm{~mm}$ (Fa Testo, Lenzkirch, Germany), the sampling rate was $0.5 \mathrm{~Hz}$, and aH was calculated using the following equation:

$$
\mathrm{aH}(\mathrm{mg} / \mathrm{L})=\mathrm{rH} \times(0.0387 \times \mathrm{T} 2-0.6066 \times \mathrm{T}+13.776) .{ }^{14}
$$

\section{Masks}

The same nasal mask with an identical leakage opening (Mirage SoftGel, Size M; ResMed Germany) was used. A port near the mask was opened to simulate mask leak. For each humidification circuit, nasal CPAP (nCPAP) was applied at pressures of 8 and $12 \mathrm{cmH}_{2} \mathrm{O}$ for $5 \mathrm{~min}$ each, without leakage $(\mathrm{nL})$ and with leakage $(\mathrm{wL})$. Flow through the mask vent at 8 and $12 \mathrm{cmH}_{2} \mathrm{O}$ was 28.5 and $36.5 \mathrm{~L} / \mathrm{min}$, respectively. The simulated leak increased the flow rate to 48.1 and $60.1 \mathrm{~L} / \mathrm{min}$, respectively.

\section{Assessments}

$\mathrm{rH}$ and temperature in the nasal mask during CPAP were measured over 5-min periods under each condition $\mathrm{(nH}, \mathrm{HH}$, $\mathrm{CL}$ ), using an integrated temperature and humidity sensor. 
Periods were randomized and the patient was blinded to the applied mode. After each condition the participants estimated their subjective comfort on a 5-item scale (0-4).

\section{Ambient room conditions}

Summer and winter measurements were performed during the respective seasons (with the window open in winter). Before and after each experiment, the temperature $\left(\mathrm{T},{ }^{\circ} \mathrm{C}\right)$ and $\mathrm{rH}$ of room air were recorded using the same sensor as in the mask.

\section{Statistical analysis}

Results are presented as mean $\pm \mathrm{SD}$. The nonparametric Wilcoxon signed rank test and the Mann-Whitney U test were used to compare paired and unpaired parameters. Statistical analyses were carried out using WinSTAT ${ }^{\circledR}$ software (Cambridge, MA, USA). A two-sided $p$-value of $<0.05$ was considered statistically significant.

\section{Ethical approval}

All procedures performed in studies involving human participants were in accordance with the ethical standard of the institutional and/or national research committee and with the 1964 Declaration of Helsinki and its later amendments or comparable ethical standards.

\section{Results}

\section{Participants}

Eighteen patients with OSA were included. Seven patients were assessed during winter group and 11 during summer. Patient demographic and clinical data are shown in Table 1.

\section{Room temperature and humidity}

In summer, mean ambient room temperature was $20.7 \pm$ $0.46^{\circ} \mathrm{C}$ and $\mathrm{rH} 58.8 \pm 5.2 \%$; corresponding values for winter were $14.3 \pm 0.84^{\circ} \mathrm{C}$ and $\mathrm{rH} 44.6 \pm 8.8 \%$.

Table I Subject characteristics

\begin{tabular}{llll}
\hline Characteristics & $\begin{array}{l}\text { Overall } \\
(\mathbf{n}=I 8)\end{array}$ & $\begin{array}{l}\text { Summer } \\
(\mathbf{n}=I \mathrm{I})\end{array}$ & $\begin{array}{l}\text { Winter } \\
(\mathbf{n}=7)\end{array}$ \\
\hline Age, years & $54.3 \pm 8.5$ & $54.5 \pm 7.9$ & $54.0 \pm 7.8$ \\
Height, cm & $179.9 \pm 8.4$ & $179.4 \pm 5.2$ & $180.9 \pm 5.1$ \\
Weight, kg & $102.7 \pm 20.6$ & $98.9 \pm 17.0$ & $108.6 \pm 15.1$ \\
$\mathrm{BMI}, \mathrm{kg} / \mathrm{m}^{2}$ & $31.6 \pm 5.4$ & $30.7 \pm 4.6$ & $33.1 \pm 4.5$ \\
ESS score & $9.8 \pm 5.9$ & $8.9 \pm 5.8$ & $11.3 \pm 5.0$ \\
AHI baseline, /h & $31.9 \pm 22.0$ & $26.6 \pm 21.3$ & $41.5 \pm 21.0$ \\
CPAP, $\mathrm{cmH}_{2} \mathrm{O}$ & $9.0 \pm 2.4$ & $8.6 \pm 2.2$ & $9.6 \pm 2.8$ \\
\hline
\end{tabular}

Notes: Values are mean \pm standard deviation.

Abbreviations: BMI, body mass index; ESS, Epworth Sleepiness Scale; AHI, apneahypopnea index; CPAP, continuous positive airway pressure.

\section{CPAP without humidification $(\mathrm{nH})$}

Compared with summer, aH inside the mask was significantly lower during winter. Increasing flows as a result of increasing pressure and leakage were associated with further decreases in $\mathrm{aH}$ in both summer and winter (Table 2).

\section{CPAP with controlled heated humidification $(\mathrm{HH})$}

There was a significant increase in $\mathrm{aH}$ with $\mathrm{HH}$ versus $\mathrm{nH}$ during both summer and winter. The relative difference in $\mathrm{aH}$ with $\mathrm{HH}$ vs. $\mathrm{nH}$ was significantly greater in winter (Table 2). Based on the values obtained, the $\mathrm{HH}$ system appeared able to adequately compensate for additional mask leak added to the circuit, stabilizing temperature and humidity.

\section{CPAP with controlled humidification and tube heating climate line $(\mathrm{CL})$}

$\mathrm{aH}$ values during the use of $\mathrm{CL}$ were similar to those during use of HH (Table 2). Temperature in the mask was significantly higher $(p<0.05)$ and aH was significantly lower in summer vs. winter; $\mathrm{rH}$ was lower during winter but comparisons with summer values were not statistically significant.

\section{Between-group differences in humidity}

In summer, $\mathrm{rH}$ was significantly higher in both the $\mathrm{HH}$ and CL conditions compared with $\mathrm{nH}$, and with $\mathrm{HH}$ vs. CL (all $p<0.05)$. However, during winter, $\mathrm{rH}$ in the $\mathrm{CL}$ group was $<80 \%$ and only significantly increased compared with $\mathrm{nH}$ at a CPAP pressure of $8 \mathrm{cmH}_{2} \mathrm{O}(p<0.05)$. In winter, only $\mathrm{HH}$ was associated with an $\mathrm{rH}$ above $80 \%(p<0.05$ vs. $\mathrm{nH}$ and $\mathrm{CL}$ ) but values were numerically lower than those during summer. Levels of aH were similar with both $\mathrm{HH}$ and $\mathrm{CL}$, and were both significantly increased compared with $\mathrm{nH}$ at both CPAP pressures (all $p<0.05$ ). However, as for $\mathrm{rH}$, values for aH were numerically lower in winter in all applied humidification groups.

\section{Relationship between temperature and humidity}

The relationship of both $\mathrm{rH}$ and $\mathrm{aH}$ to $\mathrm{T}$ is represented graphically in Figure 1. In winter, $\mathrm{rH}$ was always above the dew point in the $\mathrm{HH}$ group, sometimes in the $\mathrm{CL}$ group and never in the $\mathrm{nH}$ group. Under summer conditions, $\mathrm{rH}$ was above the dew point more often, apart from in the $\mathrm{nH}$ group. Absolute humidity was almost never above the dew point in winter in any group, whereas in most patients in the $\mathrm{HH}$ and CL group the aH was above the dew point in winter. 
Table 2 Relative humidity $(\mathrm{rH})$, temperature $(\mathrm{T})$ and absolute humidity $(\mathrm{aH})$ during continuous positive airway pressure (CPAP) therapy under different humidification conditions, with and without additional mask leakage, at two pressure levels $\left(8\right.$ and $\left.12 \mathrm{cmH}_{2} \mathrm{O}\right)$, in summer and winter

\begin{tabular}{|c|c|c|c|c|c|c|c|c|}
\hline \multirow[t]{3}{*}{ Setting } & \multicolumn{4}{|l|}{ Summer } & \multicolumn{4}{|l|}{ Winter } \\
\hline & \multicolumn{2}{|l|}{$8 \mathrm{cmH}_{2} \mathrm{O}$} & \multicolumn{2}{|l|}{$12 \mathrm{cmH}_{2} \mathrm{O}$} & \multicolumn{2}{|l|}{$8 \mathrm{cmH}_{2} \mathrm{O}$} & \multicolumn{2}{|l|}{$12 \mathrm{cmH}_{2} \mathrm{O}$} \\
\hline & $\begin{array}{l}\text { No mask } \\
\text { leak }\end{array}$ & $\begin{array}{l}\text { With mask } \\
\text { leak }\end{array}$ & $\begin{array}{l}\text { No mask } \\
\text { leak }\end{array}$ & $\begin{array}{l}\text { With mask } \\
\text { leak }\end{array}$ & $\begin{array}{l}\text { No mask } \\
\text { leak }\end{array}$ & $\begin{array}{l}\text { With mask } \\
\text { leak }\end{array}$ & $\begin{array}{l}\text { No mask } \\
\text { leak }\end{array}$ & $\begin{array}{l}\text { With mask } \\
\text { leak }\end{array}$ \\
\hline \multicolumn{9}{|c|}{ No humidification } \\
\hline $\mathrm{rH}, \%$ & $74.2 \pm 6.6$ & $72.0 \pm 6.9$ & $70.1 \pm 7.9$ & $68.5 \pm 7.0$ & $70.7 \pm 5.7$ & $68.3 \pm 5.9$ & $68.6 \pm 5.2$ & $67.0 \pm 4.2^{*}$ \\
\hline $\mathrm{T},{ }^{\circ} \mathrm{C}$ & $26.5 \pm 0.8$ & $26.5 \pm 0.8$ & $26.2 \pm 0.7$ & $26.2 \pm 0.6$ & $21.5 \pm 0.9^{*}$ & $21.7 \pm 0.9^{*}$ & $21.2 \pm 1.1^{*}$ & $21.2 \pm 1.1^{*}$ \\
\hline $\mathrm{aH}, \mathrm{mg} / \mathrm{L}$ & $18.4 \pm 1.7$ & $18.0 \pm 1.9$ & $17.2 \pm 1.9$ & $16.8 \pm 1.7$ & $13.2 \pm 1.5^{*}$ & $12.9 \pm 1.5^{*}$ & $12.7 \pm 1.6^{*}$ & $12.3 \pm 0.9^{*}$ \\
\hline \multicolumn{9}{|c|}{ Controlled heated humidification } \\
\hline $\mathrm{rH}, \%$ & $93.1 \pm 3.6$ & $90.0 \pm 5.2$ & $88.6 \pm 5.7$ & $85.8 \pm 6.0$ & $93.4 \pm 3.1$ & $91.7 \pm 3.9$ & $93.3 \pm 3.4$ & $92.2 \pm 2.3$ \\
\hline $\mathrm{T},{ }^{\circ} \mathrm{C}$ & $26.9 \pm 0.7$ & $26.8 \pm 0.7$ & $26.3 \pm 0.8$ & $26.1 \pm 0.7$ & $23.3 \pm 0.8^{*}$ & $23.0 \pm 1.0^{*}$ & $22.5 \pm 1 . I^{*}$ & $22.2 \pm 1.2^{*}$ \\
\hline $\mathrm{aH}, \mathrm{mg} / \mathrm{L}$ & $23.7 \pm 1.4$ & $22.8 \pm 1.4$ & $21.8 \pm 1.8$ & $20.9 \pm 1.6$ & $19.2 \pm 0.9^{*}$ & $18.6 \pm 1 . I^{*}$ & $18.4 \pm 1.3^{*}$ & $17.9 \pm 1.4^{*}$ \\
\hline \multicolumn{9}{|c|}{ Controlled heated humidification with heated tube climate line } \\
\hline $\mathrm{rH}, \%$ & $82.8 \pm 8.2$ & $81.3 \pm 6.7$ & $82.5 \pm 5.9$ & $8 I .1 \pm 5.3$ & $77.7 \pm 4.2$ & $75.2 \pm 3.1$ & $77.3 \pm 2.6$ & $77.0 \pm 3.2$ \\
\hline $\mathrm{T},{ }^{\circ} \mathrm{C}$ & $28.1 \pm 0.8$ & $28.2 \pm 0.8$ & $27.9 \pm 0.6$ & $27.8 \pm 0.7$ & $26.4 \pm 1.0^{*}$ & $26.2 \pm 1.0^{*}$ & $25.9 \pm 0.6^{*}$ & $25.7 \pm 0.5^{*}$ \\
\hline $\mathrm{aH}, \mathrm{mg} / \mathrm{L}$ & $22.6 \pm 2.5$ & $22.3 \pm 1.9$ & $22.3 \pm 1.9$ & $21.8 \pm 1.6$ & $19.2 \pm 1.4^{*}$ & $18.4 \pm 1.2^{*}$ & $18.6 \pm 0.9^{*}$ & $18.3 \pm 1.1^{*}$ \\
\hline
\end{tabular}

Notes: Data are presented as mean \pm standard deviation. ${ }^{*} p<0.0$ I vs. summer.

\section{Subjective assessment}

Patients were asked about their comfort after each experimental condition using a 5 -item scale $(0=$ uncomfortable, 4 = comfortable). Patients were blinded to the condition. The highest comfort was achieved during the CL condition in the winter assessments, regardless of pressure and leakage (Figure 2).

\section{Discussion}

In this study, differences in aH between the mask and lower respiratory tract were greatest in the presence of mask leak and the absence of $\mathrm{HH}$. Use of $\mathrm{HH}$ that can take into account ambient temperature and humidity effectively increased mask $\mathrm{aH}$ in both summer and winter and compensated for the leakage, but was most effective during winter. Additional heated tubing did not increase aH above the level achieved with $\mathrm{HH}$, but it did significantly increase temperature and decrease $\mathrm{rH}$, and therefore had the advantage of keeping $\mathrm{rH}$ well below the dew point, preventing tube condensation.

Our results showed marked variation in the performance of CPAP under summer and winter conditions. The seasonal variations might reflect what happens in different regions around the world. They could also provide one explanation for discrepancies between the results of previous studies looking at the role of humidification during CPAP.

It is our clinical experience that patients report more undesirable side effects from CPAP therapy during winter. The results of the current study do suggest that ambient temperature and humidity are important factors influencing mask humidity. It would appear that leakage and lower ambient aH during the colder months can dehydrate the nasal mucosa. Heating and humidification conditions the inspired gases to body temperature and pressure saturated (BTPS) of $37^{\circ} \mathrm{C}$ and $100 \% \mathrm{rH}$, corresponding to an aH of $44.3 \mathrm{mg} / \mathrm{L}$. This is thermodynamically neutral, ${ }^{15}$ minimizes water loss and preserves the integrity of mucosal membrane function. ${ }^{16}$

A low ambient $\mathrm{aH}$ and $\mathrm{T}$ over a longer time can contribute to nasal dehydration and discomfort. We implemented a visual scale to display the patient's subjective comfort during the various conditions, certainly limited by the short period each condition was applied.

During CPAP at both pressure levels used in this study, $\mathrm{CL}$ significantly improved $\mathrm{aH}$ in the mask compared with no humidification, but not compared with $\mathrm{HH}$. However, temperature in the mask was augmented by $2-3^{\circ} \mathrm{C}$ and $\mathrm{rH}$ decreased by $>10 \%$ when a heated tube was added compared with $\mathrm{HH}$. Using an unheated tube during CPAP treatment at an ambient temperature of $15^{\circ} \mathrm{C}$ produced a temperature difference of about $4^{\circ} \mathrm{C}$ between the tube at the outlet of the humidifier and patient. ${ }^{17}$ This represents a $10-15 \%$ increase in $\mathrm{rH}$ as the air stream cools down by $>4^{\circ} \mathrm{C}$. Under these conditions, the dew point can be exceeded and condensation could form in the tube and mask. To avoid condensation in unheated tubes, the $\mathrm{rH}$ of gases at the humidifier should not exceed $80-85 \%$. However, tube heating means that such 

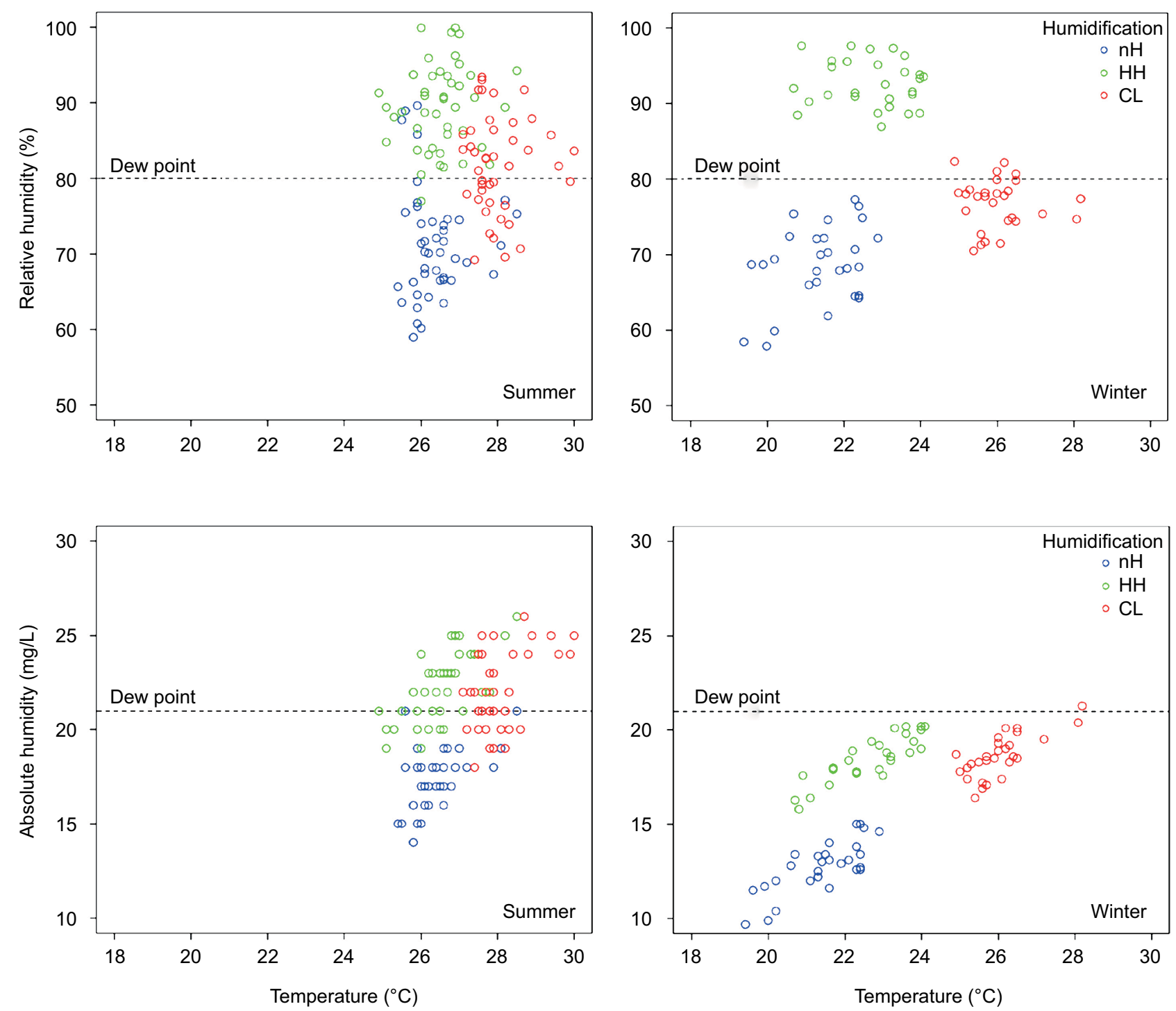

Figure I Relationship between temperature and humidity.

Notes: Relative humidity $(\mathrm{rH} ; \%)$ and absolute humidity $(\mathrm{aH}, \mathrm{mg} / \mathrm{L})$ dependent on temperature under winter and summer conditions during continuous positive airway pressure (CPAP) therapy with no humidification ( $\mathrm{nH}$; blue circles), standard heated humidification ( $\mathrm{HH}$; green circles) and heated tube humidification (CL; red circles). Data are combined for CPAP at 8 and $12 \mathrm{cmH}_{2} \mathrm{O}$, with and without leakage

Abbreviation: $\mathrm{CL}$, climate line.

restrictions are not necessary and water condensation can be avoided.

In about one-fifth of OSA syndrome patients, the soft palate seal to separate the oral cavity from the pharynx is not complete and mouth flow can occur for several minutes. ${ }^{18}$ During CPAP at $12 \mathrm{cmH}_{2} \mathrm{O}$, with and without leakage, $\mathrm{rH}$ in our study fell from $88.6 \pm 5.7 \%$ to $85.8 \pm 6.0 \%$. In a study which simulated mouth leak, a decrease in $\mathrm{rH}$ from $82 \pm 12 \%$ to $63 \pm 9 \%$ was reported. ${ }^{10}$ We assume that the experimental leakage flow in our study was below the order of magnitude that can occur with mouth breathing. The additional artificial leak in the nasal mask could almost be compensated for by
$\mathrm{HH}$ and aH was not reduced to any relevant extent compared with mask breathing without leakage.

Data from a previous study showed that during CPAP at $8 \mathrm{cmH}_{2} \mathrm{O}$ without humidification, $\mathrm{aH}$ in the anterior turbinate region was at $15.3 \pm 2.2 \mathrm{mg} / \mathrm{L}$. When a nasal mask leak was added, the aH decreased by $1.5 \mathrm{mg} / \mathrm{L} .{ }^{19}$ In the current study, under the same CPAP conditions but a smaller nasal mask leak, aH in the mask was higher $(18.4 \mathrm{mg} / \mathrm{L})$ and the decrease associated with mask leak smaller $(0.4 \mathrm{mg} / \mathrm{L})$.

In intensive care medicine, aH values of $>23 \mathrm{mg} / \mathrm{L}$ are regarded as necessary to prevent drying of lower airways in intubated patients. ${ }^{20,21}$ It is expected that lower humidity 
Humidity subjective

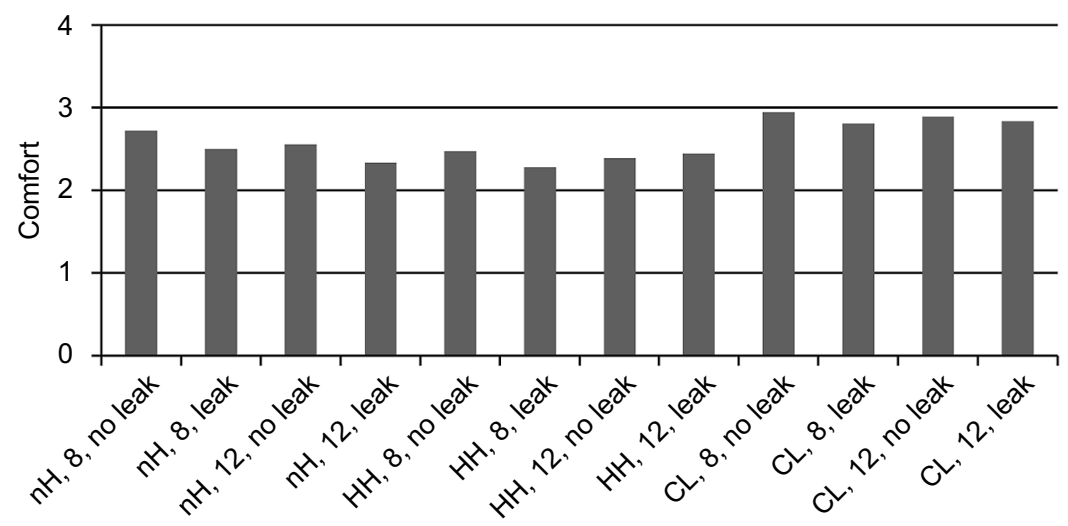

Temperature subjective

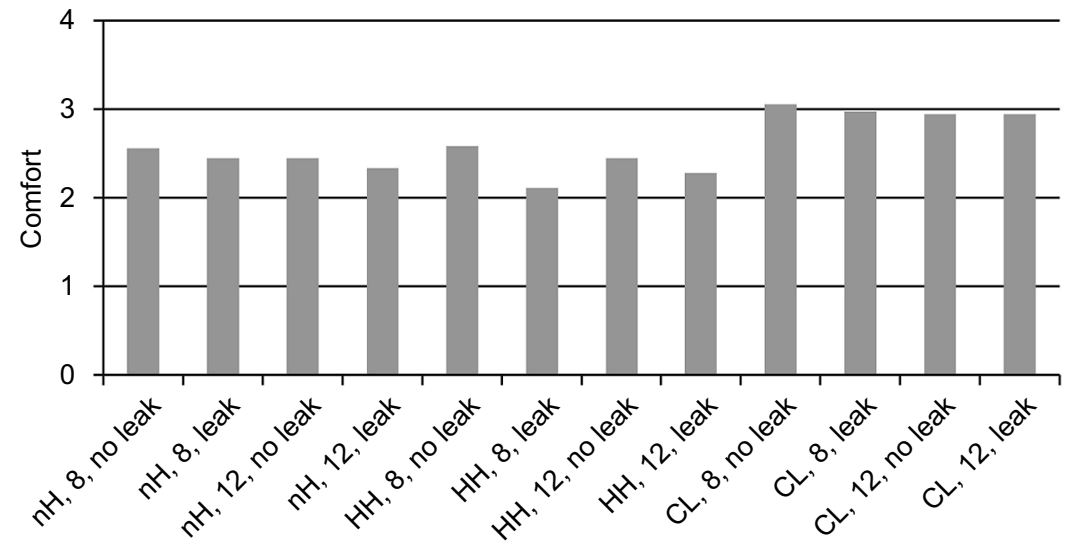

Figure 2 Overall subjective humidity and temperature evaluation during the applied pressure and leakage conditions.

Abbreviations: $\mathrm{nH}$, no humidity; $\mathrm{HH}$, heated humidity; $\mathrm{CL}$, climate line $(0=$ uncomfortable, $5=$ comfortable).

values would be tolerated during nasal CPAP therapy because the humidification capacity of the nasal mucosa is maintained. ${ }^{22}$ Richards et al found that maximum improvement of nasal resistance occurred at an aH of $21 \mathrm{mg} / \mathrm{L} .{ }^{23}$ In this study, mean aH during $\mathrm{CPAP}$ at $8 \mathrm{cmH}_{2} \mathrm{O}$ without $\mathrm{HH}$ during winter was $13.2 \mathrm{mg} / \mathrm{L}$, markedly below the $80 \% \mathrm{rH}$ threshold. $\mathrm{HH}$ significantly increased mean aH to $19.2 \mathrm{mg} / \mathrm{L}$ during winter and to $23.7 \mathrm{mg} / \mathrm{L}$ during summer conditions.

A study found that although $\mathrm{HH}$ significantly improved nasopharyngeal symptoms, it did not influence a subject's willingness to continue CPAP, leading researchers to conclude that $\mathrm{HH}$ was not required at the initiation of CPAP therapy. ${ }^{24}$ However, significant improvements in compliance have been documented with the use of $\mathrm{HH} .{ }^{10}$ In addition, there is a consistent relationship between humidification and improvement of nasal symptoms. ${ }^{7,9,24}$

The lack of a clear relationship between humidification and CPAP compliance is most likely because compliance is a multi-factorial issue, and a patient's requirement for humidification is also influenced by multiple factors including mask and mouth leak, ambient conditions, and CPAP pressures. ${ }^{25}$ It is also important to consider that previous studies used older models of humidifiers. Newer humidifier models with heated tubing have the ability to measure and adapt to ambient conditions and better optimize humidity delivery without causing condensation.

Our results show that the most effective humidification is achieved in summer conditions, with $\mathrm{HH}$ added to the circuit, no mask leak, and a heated tube. If patients do experience mask or mouth leak, or nasal symptoms, humidification should be offered. Subject age and the presence of chronic disease of the nasal mucosa should be taken into account as factors of the need for a heated humidifier. ${ }^{4,26}$ If tube condensation is an issue during standard heated humidification then use of a heated tube is recommended.

\section{Limitations}

One limitation of this study was the gap between study conditions due to experiments being conducted seasonally. Therefore, conditions may not have been identical for all subjects due to uncontrolled atmospheric conditions, and there may have been time biases. Creation of artificial 
"winter" and "summer" conditions would have allowed the study to be conducted over a shorter timeframe. However, measurements during actual summer and winter should be more representative of reality in clinical practice.

\section{Conclusion}

Winter conditions are associated with a clinically relevant reduction in aH in the mask during CPAP therapy, especially at higher pressures and in the presence of mask leak. The addition of heated humidification significantly increases $\mathrm{aH}$ inside the mask in both winter and summer (with and without leak). HH with heated tube raises temperature and decreases $\mathrm{rH}$ in the mask, and can be used to avoid condensation in the tube. The importance of seasonal conditions for CPAP delivery and use of $\mathrm{HH}$ need to be studied further and considered in future clinical trials.

\section{Acknowledgment}

The study was supported by uncommitted fund from ResMed. ResMed had no influence on study design, data management and analysis.

\section{Disclosure}

$\mathrm{G}$ Nilius has received research funding from Fisher \& Paykel Healthcare, Heinen und Löwenstein, and Weinmann; this has gone into department funds. H Woehrle and A Graml are employees of ResMed. KJ Franke, U Domanski, and M Schroeder have no financial or other potential conflicts of interest in this work.

\section{References}

1. Engleman HM, Asgari-Jirhandeh N, McLeod AL, Ramsay CF, Deary IJ, Douglas NJ. Self-reported use of CPAP and benefits of CPAP therapy: a patient survey. Chest. 1996;109(6):1470-1476.

2. Hoffstein V, Viner S, Mateika S, Conway J. Treatment of obstructive sleep apnea with nasal continuous positive airway pressure. Patient compliance, perception of benefits, and side effects. Am Rev Respir Dis. 1992;145(4 Pt 1):841-845.

3. Pepin JL, Leger P, Veale D, Langevin B, Robert D, Lévy P. Side effects of nasal continuous positive airway pressure in sleep apnea syndrome. Study of 193 patients in two French sleep centers. Chest. 1995;107(2):375-381.

4. Rakotonanahary D, Pelletier-Fleury N, Gagnadoux F, Fleury B. Predictive factors for the need for additional humidification during nasal continuous positive airway pressure therapy. Chest. 2001;119(2): 460-465.

5. Bachour A, Maasilta P. Mouth breathing compromises adherence to nasal continuous positive pressure therapy. Chest. 2004;126(4): $1248-1254$.

6. Ruhle KH, Franke KJ, Domanski U, Nilius G. Quality of life, compliance, sleep and nasopharyngeal side effects during CPAP therapy with and without controlled heated humidification. Sleep Breath. 2011;15(3):479-485.
7. Mador MJ, Krauza M, Pervez A, Pierce D, Braun M. Effect of heated humidification on compliance and quality of life in patients with sleep apnea using nasal continuous positive airway pressure. Chest. 2005;128(4):2151-2158.

8. Neill AM, Wai HS, Bannan SP, Beasley CR, Weatherall M, Campbell AJ. Humidified nasal continuous positive airway pressure in obstructive sleep apnoea. Eur Respir J. 2003;22(2):258-262.

9. Massie CA, Hart RW, Peralez K, Richards GN. Effects of humidification on nasal symptoms and compliance in sleep apnea patients using continuous positive airway pressure. Chest. 1999;116(2):403-408.

10. Smith I, Lasserson TJ. Pressure modification for improving usage of continuous positive airway pressure machines in adults with obstructive sleep apnoea. Cochrane Database System Rev. 2009;4:CD003531.

11. Martins De Araujo MT, Vieira SB, Vasquez EC, Fleury B. Heated humidification or face mask to prevent upper airway dryness during continuous positive airway pressure therapy. Chest. 2000;117(1):142-147.

12. Nilius G, Domanski U, Franke KJ, Ruhle KH. Impact of a controlled heated breathing tube humidifier on sleep quality during CPAP therapy in a cool sleeping environment. Eur Respir J. 2008;31(4):830-836.

13. Mortimore IL, Whittle AT, Douglas NJ. Comparison of nose and face mask CPAP therapy for sleep apnoea. Thorax. 1998;53(4):290-292.

14. Chiumello D, Chierichetti M, Tallarini F, et al. Effect of a heated humidifier during continuous positive airway pressure delivered by a helmet. Crit Care. 2008;12(2):R55.

15. Ryan SN, Rankin N, Meyer E, Williams R. Energy balance in the intubated human airway is an indicator of optimal gas conditioning. Crit Care Med. 2002;30(2):355-361.

16. Williams R, Rankin N, Smith T, Galler D, Seakins P. Relationship between the humidity and temperature of inspired gas and the function of the airway mucosa. Crit Care Med. 1996;24(11):1920-1929.

17. Ruhle KH, Domanski U, Schroder M, Franke KJ, Nilius G. [Heated humidification during CPAP with and without tube insulation]. Pneumologie. 2010;64(5):316-319. German.

18. Ruhle KH, Nilius G. Mouth breathing in obstructive sleep apnea prior to and during nasal continuous positive airway pressure. Respiration. 2008;76(1):40-45.

19. Fischer Y, Keck T, Leiacker R, Rozsasi A, Rettinger G, Gruen PM. Effects of nasal mask leak and heated humidification on nasal mucosa in the therapy with nasal continuous positive airway pressure (nCPAP). Sleep Breath. 2008;12(4):353-357.

20. Thomachot L, Viviand X, Lagier P, Dejode JM, Albanèse J, Martin C. Measurement of tracheal temperature is not a reliable index of total respiratory heat loss in mechanically ventilated patients. Crit Care. 2001;5(1):24-30.

21. Wiest GH, Foerst J, Fuchs FS, Schmelzer AH, Hahn EG, Ficker JH. In vivo efficacy of two heated humidifiers used during CPAP-therapy for obstructive sleep apnea under various environmental conditions. Sleep . 2001;24(4):435-440.

22. Rouadi P, Baroody FM, Abbott D, Naureckas E, Solway J, Naclerio RM. A technique to measure the ability of the human nose to warm and humidify air. $J$ Appl Physiol. 1999;87(1):400-406.

23. Richards GN, Cistulli PA, Ungar RG, Berthon-Jones M, Sullivan CE. Mouth leak with nasal continuous positive airway pressure increases nasal airway resistance. Am J Respir Crit Care Med. 1996;154(1): 182-186.

24. Yu CC, Luo CM, Liu YC, Wu HP. The effects of heated humidifier in continuous positive airway pressure titration. Sleep Breath. 2013;17(1): $133-138$.

25. Ryan S, Doherty LS, Nolan GM, McNicholas. Effects of heated humidification and topical steroids on compliance, nasal symptoms, and quality of life in patients with obstructive sleep apnea syndrome using nasal continuous positive airway pressure. J Clin Sleep Med. 2009;5(5):422-427.

26. Esquinas Rodriguez AM, Scala R, Soroksky A, et al. Clinical review: humidifiers during non-invasive ventilation - key topics and practical implications. Crit Care. 2012;16(1):203 


\section{Publish your work in this journal}

Nature and Science of Sleep is an international, peer-reviewed, open access journal covering all aspects of sleep science and sleep medicine, including the neurophysiology and functions of sleep, the genetics of sleep, sleep and society, biological rhythms, dreaming, sleep disorders and therapy, and strategies to optimize healthy sleep. The manuscript management system is completely online and includes a very quick and fair peer-review system, which is all easy to use. Visit http://www. dovepress.com/testimonials.php to read real quotes from published authors.

Submit your manuscript here: https://www.dovepress.com/nature-and-science-of-sleep-journal 